\title{
Scaling Fabrication Methods from Micro to Nano
}

\author{
M. CoOKE*
}

Oxford Instruments Plasma Technology Ltd., UK

Researchers need tools that will operate flexibly over many different length scales. The whole idea of nanotechnology is to unlock useful phenomena which only gain significance at length scales below $100 \mathrm{~nm}$, so the tools used to manipulate matter at these scales must control dimensions with a precision ten to one hundred times smaller still. Oxford Instruments work in this field, and its customers benefit from the precision of their techniques.

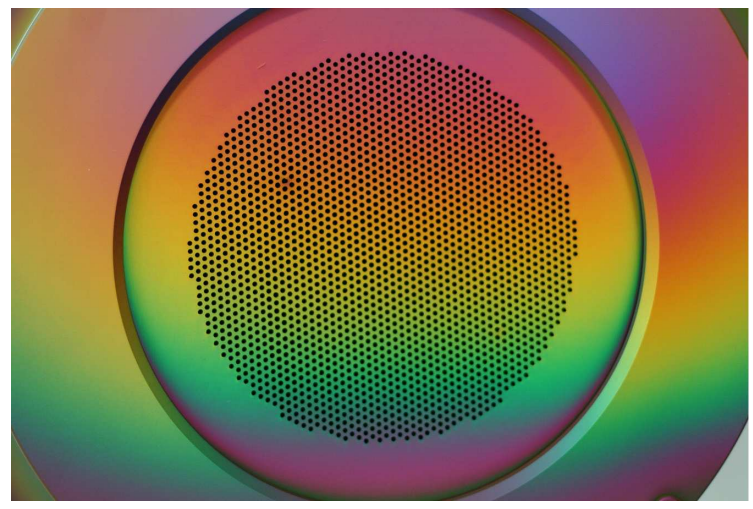

Fig. 1. Ion beam grids, shown coated with $\mathrm{SiO}_{2}$.

In layer deposition, Oxford Instruments Plasma Technology (OIPT) offers one of the widest ranges of technologies:

- Magnetron sputtering or physical vapour deposition - PVD;

- Thermal chemical vapour deposition - CVD;

- Plasma enhanced chemical vapour deposition PECVD;

- High density plasma CVD, using an induction coupled plasma - ICP-CVD;

- Ion beam deposition - IBD;

- Atomic layer deposition - ALD;

- Plasma enhanced ALD - PEALD.

\footnotetext{
* e-mail: Plasma.technology@oxinst.com
}

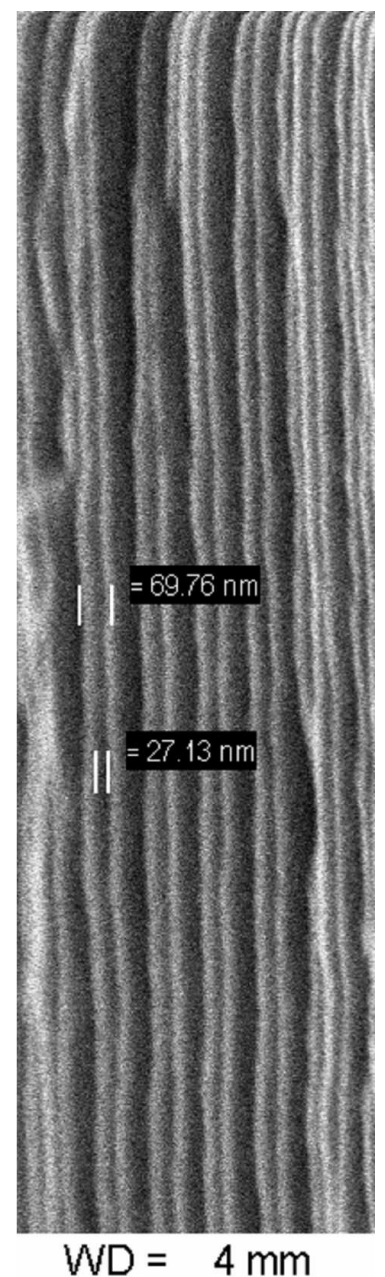

Fig. 2. $\mathrm{ZnO}$ nanowires, created by ALD into the pores of anodised aluminium.

These are distinguished by the deposition temperature, the source materials, and typical deposition rates. The techniques used at the smallest scales tend to be those with the lower deposition rates, for precision and at the lower temperatures, to maintain sharp interfaces between dissimilar materials. They also demand a lower level of background gas, to maintain material purity in the face of competition between wanted and unwanted species arriving at the surface. With every deposition process, there 
is also the need for a cleaning method to remove material; for example the ion beam grids (Fig. 1) become coated. Such material needs to adhere well to keep particle levels low during processing.

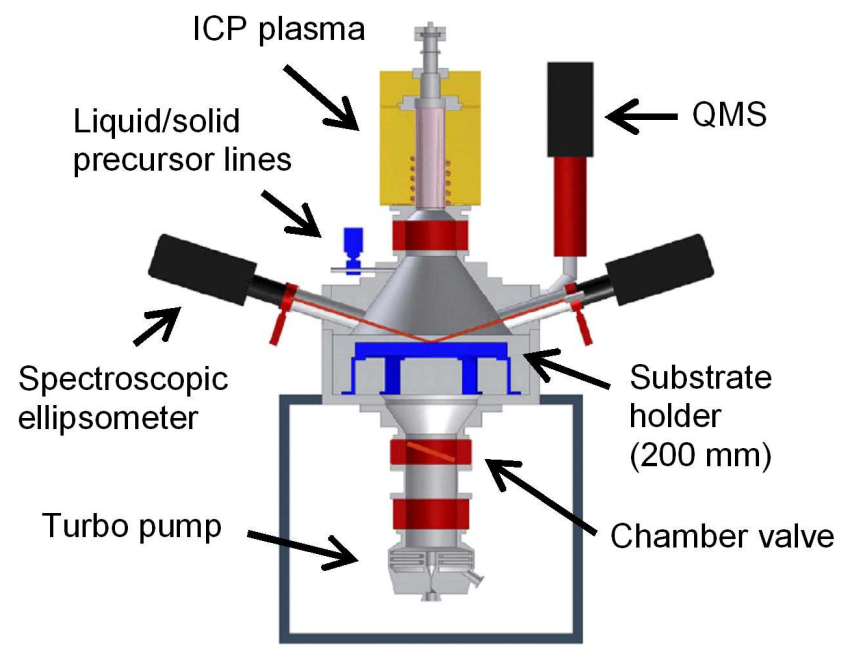

Fig. 3. PEALD chamber schematic.
It is noticeable in Table how plasma and high density induction coupled plasma drive the process temperatures down, getting similar material quality to thermally driven CVD processes but at substantially lower temperatures. Many of these techniques will be very familiar, but in Fig. 3 we show a recent introduction - plasma enhanced atomic layer deposition.

Atomic layer deposition is remarkably conformal: it maintains the same thickness on fully exposed top surfaces and on deeply re-entrant surfaces, unlike PVD and IBD, which are far more directional. It has been shown that anodised aluminium can be used as a template for atomic layer deposition, by filling the anodising pores with zinc oxide nanowires using ALD (Fig. 2). When the anodising is removed by a selective wet etch, extraordinarily thin, tall $\mathrm{ZnO}$ structures remain.

PEALD uses an ICP plasma adjacent to the wafer, but not strongly bombarding it with energetic particles - its use is as a rich source of reactive radicals. In keeping with the need for lower background gases in depositing the thinnest layers, OIPT fit a turbomolecular pump to their PEALD tools; the plasma source also gives the facility to perform light etching in situ.

Typical parameters of the technologies used.

\begin{tabular}{l|c|c|l}
\hline \hline Method & $\begin{array}{l}\text { Substrate } \\
\text { temperature }\end{array}$ & $\begin{array}{l}\text { Deposition } \\
\text { rates }[\mathrm{nm} / \mathrm{min}\end{array}$ & $\begin{array}{l}\text { Typical applications and special } \\
\text { features }\end{array}$ \\
\hline PVD & $20-300^{\circ} \mathrm{C}$ & $5-500$ & $\begin{array}{l}\text { any materials with high melting } \\
\text { point targets available; very versatile }\end{array}$ \\
\hline CVD & $400-800^{\circ} \mathrm{C}$ & $10-100$ & $\begin{array}{l}\text { polycrystalline silicon, } \mathrm{SiO}_{2} \text { silicon } \\
\text { nanowires, carbon nanotubes }\end{array}$ \\
\hline PECVD & $200-400^{\circ} \mathrm{C}$ & $5-500$ & $\begin{array}{l}\text { best known for silicon nitride and } \\
\text { oxide, many other processes available }\end{array}$ \\
\hline ICP-CVD & $50-150{ }^{\circ} \mathrm{C}$ & $5-100$ & $\begin{array}{l}\text { SiO } O_{2} \text { and silicon nitride materials } \\
\text { equivalent to PECVD films, but } \\
\text { deposited much cooler }\end{array}$ \\
\hline IBD & $50-200{ }^{\circ} \mathrm{C}$ & $1-10$ & $\begin{array}{l}\text { high precision thin layers, optical } \\
\text { coatings. Reactive deposition of oxides } \\
\text { and nitrides from metal targets. }\end{array}$ \\
\hline ALD & $100-300^{\circ} \mathrm{C}$ & $0.1-3$ & $\begin{array}{l}\text { cyclical exposure to chemical gases } \\
\text { which produce self-limiting surface } \\
\text { reactions. Many oxide materials }\end{array}$ \\
\hline PEALD & $50-300^{\circ} \mathrm{C}$ & $0.1-3$ & $\begin{array}{l}\text { as ALD, but uses plasma instead } \\
\text { of water vapour }\end{array}$ \\
\hline
\end{tabular}

